\title{
Valor pronóstico de la densidad microvascular y de la expresión del VEGF, EGFR y HIF-1 $\alpha$ en pacientes con cáncer de cérvix localmente avanzado tratados con quimiorradiación (ONCOLGroup) $)^{\mathrm{s}}$
}

\author{
Prognostic value of microvascular density and \\ expression of VEGF, EGFR and HIF-1 $\alpha$ \\ in patients with locally advanced cervical cancer treated with \\ chemoradiation (ONCOLGroup) $)^{\S}$
}

\author{
Andrés Felipe Cardona*, luis Fernando Jaramillo, Pilar Archila, Delma \\ Zea, ludovic Reveiz, Hernán Carranza, Jorge Miguel Otero, Carlos \\ Vargas, Henry Becerra, Andrés Acevedo, Silvia Serrano, Diana Torres, \\ Ricardo Brugés, Álvaro Muñoz, Leonardo Rojas, Vanesa Ospina, Carlos \\ CASTRO • BOGOTÁ, D.C. (COLOMBiA) \\ ANTONIO ARELLANO-Tolivar • BARCELONA (EsPaña)
}

\section{Resumen}

Introducción: en Colombia el carcinoma de cuello uterino representa la segunda causa de muerte por cáncer entre las mujeres.

Objetivo: describir el valor pronóstico de la densidad microvascular (DMV) y de la expresión proteica de varios genes relacionados con la supervivencia y proliferación del cáncer de cérvix localmente avanzado tratado con quimiorradiación/braquiterapia intracavitaria. Se estimaron la tasa de respuesta global (TRG), la supervivencia libre de progresión (SLP) y la supervivencia global (SG).

Resultados: se incluyeron 61 mujeres con una edad media de $52 \pm 10$ años; todas tenían diagnóstico de cáncer de cérvix localmente avanzado (IIA 2.3\%/IIB 47.5\%/IIIA 4.9\%/IIIB $37.7 \% /$ IVA $3.3 \% /$ no definido 3.3\%), con un volumen tumoral promedio de $6.4 \mathrm{~cm}$ (DE \pm $1.8 \mathrm{~cm}$ ) e infección por VPH en $46 \%$ de los casos; 58 sujetos (95\%) tenían un patrón escamoso, dos fueron adenocarcinomas y $>50 \%$ presentaba neoplasias moderada o pobremente diferenciadas. Todas fueron tratadas con quimiorradiación (interrupción transitoria de la teleterapia por toxicidad y otras causas en 19 y $21.4 \%$, respectivamente/media de ciclos de platino concomitante 4.8 series \pm 1.0 ) y braquiterapia ( $77 \%$ completaron el tratamiento intracavitario). La mediana para la SLP y global fue de 6.6 meses (4.0-9.1) y 30 meses (1148 ), respectivamente. Ninguna de las variables tuvo efecto sobre la SLP, mientras el análisis multivariado demostró que los niveles de expresión del VEGF ( $\mathrm{p}=0.026)$, EGFR ( $\mathrm{p}=0.030)$, y el volumen tumoral $<6 \mathrm{~cm}(\mathrm{p}=0.02)$ influyeron sobre este desenlace.

Conclusión: la tipificación de genes relacionados con angiogénesis y proliferación celular en el cáncer de cérvix localmente avanzado tratado con quimiorradiación basada en platino tiene una influencia positiva sobre el pronóstico. (Acta Med Colomb 2012; 37: 106-117)

Palabras clave: cáncer de cérvix, virus del papiloma humano, quimioterapia, radioterapia, expresión de genes, supervivencia.

\footnotetext{
Abstract

Introduction: cervical carcinoma is the second leading cause of cancer death among women in Colombia.

Objective: to describe the prognostic value of microvascular density (MVD) and protein expression of several genes related to survival and proliferation of locally advanced cervical cancer (LACC) treated with chemoradiation / intracavitary
}

Este estudio se realizó gracias al apoyo irrestricto de la Fundación para la Investigación Clínica y Molecular Aplicada del Cáncer (FICMAC; estipendio 011-2009), fue presentado localmente durante el Congreso Post ASCO-ASH 5.0 (2011) donde fue merecedor de reconocimiento a la Investigación Clínica y Translacional en Oncología. También fue enviado y presentado parcialmente en el Congreso de la European Society of Medical Oncology (ESMO 2011 - Poster\#8044).

"El trabajo hace parte del programa para la obtención del título de doctor en medicina con énfasis en genómica tumoral de Andrés Felipe Cardona, alumno de la Unidad de Oncología del Hospital Germans Trias i Pujol, Instituto Catalán de Oncología (ICO), adscrita al Departamento de Medicina de la Universidad Autónoma de Barcelona (UAB).

Dres. Andrés Felipe Cardona, Jorge Miguel Otero, Carlos Vargas, Hernán Carranza y Carlos Castro: Grupo Oncología Clínica y Translacional, Instituto de Oncología, Fundación Santa Fe de Bogotá. Laboratorio de Biología Molecular Tumoral, FICMAC. Investigadores Asociados ONCOLGroup. Bogotá, D.C.(Colombia); Dr. Luis Fernando Jaramillo: Departamento de Patología, Hospital Universitario San Ignacio, Pontificia Universidad Javeriana, Bogotá, D.C. (Colombia); Dras. Pilar Archila y Silvia Serrano: Laboratorio de Biología Molecular Tumoral, FICMAC, Bogotá, D.C. (Colombia). Investigadoras Asociadas ONCOLGroup; Dra. Delma Zea: Grupo de Radioterapia, Centro Javeriano de Oncología, Hospital Universitario San Ignacio, Pontificia Universidad Javeriana, Bogotá, D.C. (Colombia); Dr. Ludovic Reveiz: Centro Iberoamericano de la Colaboración Cochrane; Dr. Henry Becerra: Grupo Oncología Clínica y Translacional, Instituto de Oncología, Fundación Santa Fe de Bogotá, Bogotá, D.C. (Colombia); Dr. Andrés Acevedo: Grupo Hematología y Trasplante de Médula Ósea, Instituto de Oncología, Fundación Santa Fe de Bogotá, Bogotá, D.C. (Colombia); Dra. Diana Torres: Laboratorio de

Continúa página siguiente...

Correspondencia. Dr. Andrés Felipe Cardona, Grupo Oncología Clínica y Traslacional, Instituto de Oncología, Fundación Santa Fe de Bogotá, Bogotá, Colombia.

E-mail: a_cardonaz@yahoo.com; andres.cardona@fsfb. org.co

Recibido: 18/XI/2011 Aceptado: 08/VIII/2012 
Biología Molecular Tumoral, FICMAC, Bogotá, D.C. (Colombia). Investigadora Asociada ONCOLGroup. Instituto de Genética Humana, Pontificia Universidad Javeriana, Bogotá, D.C. (Colombia); Dr. Ricardo Brugés: Grupo de Oncología, Centro Javeriano de Oncología, Hospital Universitario San Ignacio, Pontificia Universidad Javeriana, Bogotá D.C. (Colombia); Dr. Álvaro Muñoz: Grupo Radioterapia, Instituto de Oncología, Fundación Santa Fe de Bogotá, Bogotá, D.C. (Colombia); Dr. Leonardo Rojas: Departamento de Oncología, Instituto Nacional de Cancerología - INCAN, México D.F. (México); Dra. Vanesa Ospina: Grupo de Oncología, Centro Javeriano de Oncología, Hospital Universitario San Ignacio, Pontificia Universidad Javeriana, Bogotá D.C. (Colombia); Dr. Antonio Arellano-Tolivar: Departamento de Radioterapia, Hospital Universitario Germans Trias i Pujol, Barcelona, Cataluña, España. brachytherapy. We estimated the overall response rate (ORR), progression-free survival (PFS) and overall survival (OS).

Results: we included 61 women with a mean age of $52 \pm 10$ years; all were diagnosed with locally advanced cervical cancer (IIA 2.3\% / IIB 47.5\% / IIIA 4.9\% / IIIB 37.7\% / IVA 3.3\% / 3.3\% undefined ), with an average tumor volume of $6.4 \mathrm{~cm}(\mathrm{SD} \pm 1.8 \mathrm{~cm})$ and HPV infection in $46 \%$ of cases. 58 subjects $(95 \%)$ had a squamous pattern; two were adenocarcinomas and $>50 \%$ had moderate or poorly differentiated neoplasms. All were treated with chemoradiation (temporary interruption of teletherapy due to toxicity, and other causes was documented in $19 \%$ and $21.4 \%$ respectively / mean of concomitant platinum cycles $4.8 \pm 1.0)$ and brachytherapy (77\% completed intracavitary treatment). The median PFS and OS was 6.6 months (4.0-9.1) and 30 months (11-48), respectively. None of the variables had an effect on the PFS, while multivariate analysis demonstrated that the levels of VEGF expression ( $p=0.026)$, EGFR $(p=0.030)$, and tumor volume $<6 \mathrm{~cm}(p=0.02)$ influenced this outcome.

Conclusion: the characterization of genes related to angiogenesis and cell proliferation in locally advanced cervical cancer treated with platinum-based chemoradiation had a positive influence on the prognosis. (Acta Med Colomb 2012; 37: 106-117)

Keywords: cervical cancer, human papillomavirus, chemotherapy, radiotherapy, gene expression, survival.

\section{Introducción}

El cáncer de cérvix es la segunda neoplasia en incidencia y mortalidad a nivel global; anualmente, esta enfermedad causa cerca de 234000 muertes, de las cuales 40000 se presentan en mujeres provenientes de países en vía de desarrollo (1). La discrepancia en la relación incidencia/mortalidad para el cáncer de cérvix entre los países con mayores y menores recursos económicos, es el resultado directo de la inversión marginal en los programas de cribado. La vacunación masiva dirigida contra el virus del papiloma humano (VPH) que se asocia con el desarrollo del $90 \%$ de las neoplasias invasivas del cérvix, podría reducir dramáticamente la morbilidad y mortalidad de esta neoplasia (2). No obstante, el elevado costo de las vacunas y las barreras políticas y logísticas para su inclusión, retrasarán la implementación universal de la inmunización (2). De igual forma, las vacunas dirigidas contra el VPH que se encuentran disponibles sólo son efectivas contra los serotipos que originan el $70 \%$ de los cánceres (3).

En los Estados Unidos, al igual que en otros países del primer mundo, la mayoría de los cánceres de cérvix se diagnostican en estado temprano $(4,5)$; de los 13458 pacientes con cáncer de cérvix incluidos en el SEER (Surverillance, Epidemiology, and End Results) entre 1973 y 1987, el 71\% tenía neoplasias estados I a IIA según la clasificación FIGO (International Federation of Gynecology and Obstetrics) (4). La gran mayoría de los países de América Latina, incluyendo Colombia, están viviendo una transición social y demográfica; los cambios más significativos en las tasas de mortalidad global en las últimas décadas, incluyen una reducción continua en los decesos infantiles y un incremento en las muertes entre los hombres menores de 45 años (6). Estos factores, en combinación con el envejecimiento de la población y su incremento global han favorecido el aumento proporcional de las mujeres, en especial, de aquellas mayores de 65 años (6). Nuestro país tiene información limitada respecto del comportamiento epidemiológico de las neoplasias más frecuentes, pese a esto, es claro que el cáncer de cérvix representa la segunda causa de muerte por esta enfermedad entre las mujeres en Colombia (6). La distribución por estados en el país es especialmente preocupante, en particular, porque el $60 \%$ de los casos incidentes corresponden con lesiones localmente avanzadas (5-7).

La gran mayoría de las mujeres con neoplasias tempranas se curan con cirugía radical con o sin la administración de radioterapia complementaria; sin embargo, las pacientes con tumores localmente avanzados (estados II a IIIB) presentan un riesgo mayor de progresión. En este subgrupo la radioterapia como intervención única permite controlar la enfermedad en 35-65\% (8). La administración concomitante de la teleterapia pélvica con quimioterapia permite incrementar el control del crecimiento tumoral, induciendo un daño subletal sobre la célula al afectar su capacidad para reparar el ADN, hecho que ocasiona profundos cambios en el metabolismo. De la misma manera, afecta el tamaño tumoral siguiendo una relación directa entre la dosis y la respuesta, que favorece la disminución en la oxigenación tisular, la inhibición de la angiogénesis y la promoción de la apoptosis al incrementar la radiosensibilidad $(9,10)$.

En 1999, el National Cancer Institute (NCI, United States of America - USA) recomendó el uso concurrente del cisplatino con la radioterapia como estándar para el tratamiento del cáncer de cérvix localmente avanzado basado en los resultados de la integración de cinco estudios clínicos fase III con asignación aleatoria (11); de éstos, dos fueron realizados de forma exclusiva en mujeres con enfermedad temprana (estados IA, II, IB y IIA) e incluyeron el uso preoperatorio y posoperatorio de radioterapia como parte del control. En los tres estudios restantes publicados por el Ginecology Oncology Group (GOG) y por el Raditation Therapy Oncology 
Group (RTOG) se incluyeron un gran número de pacientes con estados IIB, III y IVA. Estos experimentos encontraron un beneficio uniforme con el uso de la quimiorradiación que otorga un incremento absoluto en la supervivencia global (SG) a cinco años del 12\% (12).

El VPH es un virus ADN circular de $8-\mathrm{kb}$ que tiene como blanco específico las células basales de los epitelios de las mucosas; su familia está constituida por más de 100 genotipos que se clasifican de acuerdo con los elementos que infectan, y por su capacidad para generar modificaciones complejas en la información del hospedero (13). Algunos subtipos como el VPH1, infectan las células de los estratos córneos en la piel, mientras que los subtipos 6, 11, 16 y 18 comprometen la mucosa de la cavidad oral, la orofaringe, el tracto anogenital y el cérvix. Los tipos de bajo riesgo generan lesiones benignas, en contraposición a sus homólogos de alto riesgo que ocasionan neoplasias (13). El genoma del VPH está comprimido en genes tempranos y tardíos así como en regiones no codificantes, todos ellos, activos en los procesos de replicación, transcripción y carcinogénesis. Los marcos de lectura tardía codifican las proteínas de la cápside L1 y L2 que se transcriben sólo en las células infectadas. Los primeros marcos de lectura $(\mathrm{E})$ codifican de forma abierta las proteínas E1, 2, 5, 6 y 7, vinculados en la regulación de la replicación y en la expresión de otros genes. Al menos tres proteínas (E5, E6 y E7) codificadas por los virus de alto riesgo se consideran oncogénicas debido a su capacidad para inducir la transformación y el crecimiento de las células anormales. Estas moléculas proteicas tienen la capacidad de regular la función de los genes supresores de tumor mediante la derogación de la actividad de las proteínas p21, p53 y $\mathrm{pRb}$, eventos que resultan en la alteración de la apoptosis, en defectos relacionados con la reparación del ADN y del control del ciclo celular (13-15).

Desde que se reconoció el efecto de la infección persistente de los genotipos de alto riesgo del VPH sobre la probabilidad de desarrollar cáncer de cérvix se descubrió la capacidad de adhesión lineal del genoma del virus en los cromosomas del huésped, evento que suele ocurrir de forma tardía. La integración del genoma viral es al azar y ocurre con mayor predilección en los sitios donde hay cierta fragilidad. Dicha unión se produce gracias a la interrupción en la secuencia del gen E1/2 lo que produce sobreexpresión de E6 y E7 que conducen a la alteración de las principales vías supresoras de tumor $(14,15)$.

La familia de proteínas relacionadas con el factor de crecimiento del endotelio vascular (VEGF, Vascular Endothelial Growth Factor) representa un grupo heterogéneo de elementos relacionados con el estímulo y aumento de la permeabilidad vascular, el crecimiento de las células endoteliales, su migración y diferenciación (16). La sobreexpresión del VEGF se ha correlacionado con un peor pronóstico en los pacientes con carcinoma escamoso de cérvix y sus niveles en suero representan un marcador subrogado del crecimiento tumoral. Evaluaciones colposcópicas del cér- vix han encontrado vasos sanguíneos atípicos con formas irregulares y aumento de la densidad microvascular (DMV medida por la cuantificación de la expresión de CD31) que caracteriza un fenotipo más agresivo (17). La oncoproteína E6 del VPH media la inactivación del p53 promoviendo la sobreexpresión de VEGF, modulando la angiogénesis y vasculogénesis a través de TSP1 (Thromobospondin 1); esta última, es una glicoproteína de adhesión que facilita la interacción entre las células y su matriz a nivel del estroma, permitiendo la unión de moléculas como el fibrinógeno, la fibronectina, la laminina, el colágeno tipo 5 y las integrinas $\alpha 5$ y $\beta 1$, importantes en la génesis del carcinoma de cérvix.

Recientemente, Randall y colaboradores describieron la relevancia pronóstica de la densidad microvascular detectada por inmunohistoquímica en una muestra de especímenes recolectados en un experimento clínico fase III que incluyó mujeres con cáncer de cérvix tratadas con quimiorradiación. Este estudio demostró que una alta expresión de CD31 representa un factor pronóstico independiente que se asocia con una mayor supervivencia libre de progresión (SLP) y SG (17). En contraposición, Obermair reportó que el aumento en la DMV se asoció con un desenlace negativo al documentar una reducción en la tasa de SG a cinco años entre las mujeres que tuvieron un recuento mayor a 20 vasos por campo de gran aumento cercano a 35\% (18). La inconsistencia de los resultados en estos y otros estudios puede ser explicada por la heterogeneidad de la población evaluada, por el método de detección utilizado, por la estrategia para cuantificar la DMV, y por las diversas intervenciones usadas (19-21).

La proliferación de las células en los tumores cervicales también depende de una interacción dinámica con su microambiente, en particular con las estructuras vasculares. Varios estudios han demostrado que la hipoxia tumoral aumenta el flujo en las arterias uterinas beneficiando el consumo de glucosa y la alteración en la densidad capilar. La hipoxia también representa uno de los principales indicadores para el control de las células progenitoras normales y tumorales, y en el cáncer, modifica el gradiente de producción de múltiples sustancias quimiotácticas, y de otras proinflamatorias $(22,23)$.

Por otra parte, Liu y colaboradores encontraron que la sobreexpresión de HIF-1 $\alpha$ (Hypoxia Growth Factor Type $1 \alpha$ ) promueve la radiorresistencia a través de la supresión de la expresión de Bax (24), efecto que es motivado por la producción de las oncoproteínas E6 y E7 del VPH (25). Dellas y colaboradores investigaron la relación entre la expresión de HIF-1 $\alpha$ cuantificada por inmunohistoquímica, la oxigenación tumoral y los niveles de hemoglobina en una cohorte de pacientes con carcinoma de cérvix localmente avanzado tratado con radioterapia; el estudio documentó que las pacientes con especímenes negativos para el HIF-1 $\alpha$ tuvieron una mejor SG a cinco años, hallazgo que se asoció con una menor fracción intratumoral de pO2 $(<5 \mathrm{mmHg})$ (26). Estos datos han sido corroborados por múltiples estudios que han evaluado la inmunorreactividad para el HIF-1 
$\alpha$ en pacientes con cáncer de cérvix y su impacto sobre los desenlaces más relevantes (27-29).

El receptor para el factor de crecimiento epidérmico (EGFR, Epidermal Growth Factor Receptor) pertenece a la familia de receptores localizados en la membrana plasmática que presentan actividad tirosinquinasa intrínseca. Este sitio, es reconocido por varios ligandos que poseen módulos estructurales semejantes al del EGF (Epidermal Growth Factor) $(30,31)$. El EGFR se encuentra alterado en $80 \%$ de los carcinomas escamosos de cérvix y su sobreexpresión en mujeres con tumores localmente avanzado tratadas con quimiorradiación se asoció de forma negativa con la SLP. Además, la inmunorreactividad del EGFR y de su fracción fosforilada fueron útiles para predecir la respuesta al tratamiento de forma independiente al estado tumoral y al patrón histológico dominante. Esta asociación puede explicarse, al menos en parte, por el papel que tiene el receptor en el proceso de reparación del daño ocasionado sobre el ADN vía activación de la cascada de señalización PI3K/Akt (32).

A continuación se explora el valor pronóstico de varios marcadores proteicos relacionados con la proliferación (EGFR) y angiogénesis (DMV, VEGF, HIF1- $\alpha$ ) en pacientes con carcinoma de cérvix localmente avanzado tratado con quimiorradiación seguida de braquiterapia endocavitaria. De igual forma, se plantean algunas hipótesis respecto de la relevancia clínica de estos genes con la intención de explorar mecanismos novedosos de tratamiento.

\section{Pacientes}

\section{Material y métodos}

La información extraída de las historias clínicas de 61 mujeres con cáncer de cérvix localmente avanzado tratadas con quimiorradiación y braquiterapia en Bogotá, Colombia, fueron valoradas de forma independiente por los investigadores que registraron los datos en un formato diseñado para el estudio; luego fueron digitados en una base de datos donde se examinaron usando el paquete estadístico SPSS ${ }^{\circledR} 16.0$ (IBM software, Chicago, IL, EE.UU). Se consideraron y analizaron diversas variables clínicas (edad, grado de escolaridad, historia de exposición al humo por combustión del tabaco, número de años de consumo de tabaco, historia de infección por VIH o de lesiones preneoplásicas previas, el estado funcional basal cuantificado por el índice de Karnofsky, la histología y gradación tumoral, el estado tumoral, las dimensiones del primario en centímetros, la presencia de ganglios pélvicos sugestivos de compromiso metastásico, el esquema y dosis de la radioterapia pélvica y de la braquiterapia intracavitaria, la dosis y el número de ciclos de quimioterapia con cisplatino), la toxicidad de las intervenciones (cuantificada según el National Cancer Institute Common Terminology Criteria for Adverse Events - CTCAE, version 3.0, United States) (33), el estado al final del seguimiento (viva o muerta, con o sin enfermedad) y diversos desenlaces como la tasa de respuesta global (TRG), SLP, SG y la mortalidad (utilizando los criterios RECIST 1.1) (34).

\section{Inmunohistoquímica}

- Determinación de la expresión del VEFG

Se cortaron secciones de parafina con un grosor de $5 \mathrm{~mm}$, se montaron en portaobjetos de cristal recubiertos de APES (3-aminopropiltrietoxisilano) y desparafinizaron, luego fueron tratados con peróxido de hidrógeno al $0,3 \%$ en metanol para bloquear la actividad de la peroxidasa endógena. Posteriormente, se recuperó el antígeno por inmersión de las preparaciones en un tampón citrato 0,01 (citrato monohidratado $10 \mathrm{mM}$ en agua destilada, $\mathrm{pH}=6,0$ ). Después se enfriaron las preparaciones durante 15 minutos, se incubaron durante 30 minutos con suero normal de conejo (NRS, X-0902 DAKO, Carpinteria, CA, USA), se diluyeron al 1,5 en solución salina tamponada con fosfato (PBS) para reducir la tinción inespecífica de las zonas vecinas y se incubaron durante 60 minutos con VEGF antihumano (anticuerpo policlonal, $A B-293-N A$, sistemas $R \& D$, Oxford, Reino Unido) diluido al 1:100 en PBS. Después de tres lavados con PBS, las preparaciones se incubaron con anticuerpos biotinilados anticabra/conejo (RAG, E-0466 DAKO, Carpinteria, CA, USA) diluido en 1:350 durante 30 minutos. Ulteriormente, se expusieron al complejo peroxidasa biotina-estreptavidina (DAKO, Glostrup, Dinamarca) durante 30 minutos y se utilizó como cromógeno el tetracloruro de diaminobencidina (DAB) (SIGMA, Poole, Dorset, Reino Unido).

Se realizó la contratinción con hematoxilina de Mayer. Una preparación positiva sirvió como control significativo, y como control negativo se utilizó la omisión del anticuerpo primario. Para la evaluación de la expresión del VEGF se siguieron los métodos de puntuación general descritos previamente por Kimura y colaboradores (35). En resumen, usando un aumento de 200 (cámara de $0,12 \mathrm{~mm}^{2}$ ), la expresión de VEGF se graduó semicuantitativamente en dos grupos: $<10 \%$ y $\geq 10 \%$ de células tumorales teñidas como expresión negativa y positiva, respectivamente.

\section{- Determinación de la expresión del EGFR}

Siguiendo el proceso descrito para el tratamiento del tejido tumoral embebido en parafina se realizó la tinción para el EGFR usando el anticuerpo policlonal (Santa Cruz Biotechnology, Santa Cruz, California, USA) IgG de conejo dirigido contra el receptor. El anticuerpo se diluyó 1:100 en PBS. Como controles positivos se emplearon muestras de carcinomas de mama y los controles negativos se realizaron con el mismo tejido del cérvix sin exposición al anticuerpo. Los casos se consideraron como positivos si la tinción fue al menos dos veces superior (2+) en una escala de 1 a $4+$, y si $10 \%$ o más de las células tumorales estuvieron teñidas sobre el trasfondo sano o sobre el control negativo.

\section{- Determinación de la expresión del HIF-1a}

El tejido embebido en parafina se expuso al anticuerpo monoclonal anti-HIF1a (H72320; BD Transduction Laboratories, Franklin Lakes, $N J$, USA) evaluando la expresión nuclear de forma semicuantitativa siguiendo el porcentaje de 
células afectadas y la intensidad de la tinción. Los casos con menos de $10 \%$ de células positivas se consideraron negativos y el resto fueron positivos, valorando la reactividad como débil (11-50\%), moderada (51-80\%) y fuertemente positiva $(>80 \%)$. Se descartaron las áreas con necrosis, excepto si presentaban formaciones tumorales adyacentes.

\section{-Determinación de la densidad microvascular}

Las células endoteliales se tiñeron con CD31 (anticuerpo monoclonal, clon JC/70A, isotipo IGG1, kappa, M-0823, DAKO, DAKO, Carpinteria, CA, USA) en una dilución 1/40 (36). La densidad de los vasos sanguíneos se determinó en zonas con gran vascularización, en función de los criterios propuestos por Wedner y colaboradores (37). En estas áreas la densidad de la microvasculatura se midió por un analizador digital de imágenes (aumento de 200 y campo de $0,24 \mathrm{~mm}^{2}$ ), como fue descrito previamente por Tjalma y colaboradores (36).

\section{Análisis estadístico}

Los resultados se obtuvieron y describieron por medio de la determinación de frecuencias absolutas, relativas, medidas de tendencia central y de dispersión. El cruce de variables se realizó con tablas de contingencia sometidas a pruebas de dependencia y asociación usando el estadístico Ji al cuadrado $\left(\mathrm{X}^{2}\right)$ o el test exacto de Fisher cuando fue necesario. Para todos los casos, el nivel de significancia fue $p<0,05$. Las estimaciones de supervivencia se hicieron utilizando el modelo no paramétrico del límite del producto (método de Kaplan-Meier), y sus funciones se compararon mediante la prueba Log-rank. Con el fin de valorar los factores que influyeron sobre la supervivencia se realizó un análisis multivariado utilizando el modelo proporcional de Cox ("stepwise model"). Todas las pacientes consintieron el uso de la información y la realización de las pruebas de inmunohistoquímica no convencionales.

\section{Resultados}

En el estudio se incluyeron 61 mujeres con edades entre 29 y 75 años que fueron tratadas en una institución de cuarto nivel en Bogotá, Colombia. El 92\% de la población tenía menos de 65 años, la gran mayoría presentaba un estado funcional basal cuantificado por el índice de Karnofsky mayor a $70 \%$ y $61 \%$ tenía algún grado de escolaridad básica o superior. Cerca de la mitad de los sujetos en estudio no presentaban antecedentes de exposición al humo por combustión del tabaco, y en las 12 mujeres que reportaron ser fumadoras, la media de años de consumo fue de 12. En $47 \%$ de los casos no fue posible obtener datos referentes a estudios de cribado previos, y sólo se evidenció positividad para el VPH en una mínima cantidad de mujeres $(n=7)$; ninguna tenía historia de infección por VIH.

La histología dominante fue el carcinoma escamoso $(\mathrm{n}=58)$ y más de la mitad de los tumores fueron moderadamente y mal diferenciados. Al valorar la distribución según el tamaño tumoral se encontró que $51 \%$ de las mujeres $(\mathrm{n}=31)$ presentaban lesiones con un volumen superior a los 6 cm; según la clasificación FIGO, al momento del diagnóstico 2.3, 47.5, 4.9, 37.7 y $3.3 \%$ tenían lesiones estados IIA, IIB, IIIA, IIIB y IVA, respectivamente. Sólo una minoría de los casos tuvo evaluación invasiva de los ganglios pélvicos que fueron positivos en cinco mujeres. La Tabla 1 resume las características principales de la cohorte en estudio.

En 25 pacientes se interrumpió la teleterapia de forma no programada debido a toxicidad (principalmente por diarrea: 12 casos y por cistitis actínica: cuatro casos) y en 12 mujeres se detuvo el tratamiento por limitaciones asistenciales de orden administrativo. El $75 \%$ de las pacientes completó la braquiterapia de alta tasa y el número promedio de series de cisplatino administrados durante la concomitancia fue de $4(\mathrm{DE} \pm 1)$. Después de finalizar el tratamiento oncológico, $47 \%$ de las pacientes había logrado respuesta clínica e imaginológica completa, y $25 \%$ parcial. Sólo en ocho casos se documentó enfermedad estable o en progresión, y en nueve mujeres fue imposible obtener información referente al resultado final del tratamiento. La mediana de seguimiento fue de 13.2 meses, periodo en el cual se encontró progresión de la enfermedad en 31 casos. En la Tabla 2 se encuentran discriminados los desenlaces después de la administración de la quimiorradiación y de la braquiterapia endocavitaria.

La SG y la SLP en la población general fueron 30.2 (IC95\% 11.6-48.8) y 6.6 meses (IC95\% 4.0-9.1), respectivamente (Figuras 1 y 2). No se encontraron diferencias estadísticamente significativas al discriminar la SLP según el tamaño tumoral (8.7 meses para las lesiones menores de $6 \mathrm{~cm}$ y 9.1 meses para las mayores de $6 \mathrm{~cm} ; \mathrm{p}=0.85$ ), pero sí al valorar la SG según esta variable (71 meses para las lesiones menores de $6 \mathrm{~cm}$ y 24 meses para las mayores de $6 \mathrm{~cm}$; $\mathrm{p}=0.02)$ (Figura 3$)$. La SLP ( $\mathrm{p}=0.0001)$ y la SG $(\mathrm{p}=0.0001)$ fueron significativamente superiores entre las pacientes que lograron respuesta imaginológica completa; relación que no fue positiva para la SLP según el grado tumoral ( $\mathrm{p}=0.23$ ), pero si para la estadificación siguiendo la clasificación FIGO (mayor tiempo sin evidencia de progresión entre las pacientes con lesiones estados IIA y B; $\mathrm{p}=0.004)$. Los hallazgos fueron similares para la SG que también fue influenciada por el estado tumoral $(\mathrm{p}=0.01)$.

El 50.8\% de las mujeres tuvo alteraciones en la DMV, evento que no fue dominante para las lesiones de mayor gradación $(\mathrm{p}=0.26)$, en aquellas con un estado tumoral superior a II $(\mathrm{p}=0.35)$ o en las que midieron más de $6 \mathrm{~cm}$ $(\mathrm{p}=0.13)$. No hubo relación entre una DMV anormal y el tipo de respuesta $(\mathrm{p}=0.38)$, pero sí una tendencia positiva a que la infiltración vascular fuera dominante en el segmento de mujeres menores de 50 años ( $\mathrm{p}=0.06$ ). El 88 y $62 \%$ de las mujeres con DMV alterada tuvieron una alta expresión de VEGF y HIF1- $\alpha$, respectivamente; en las mujeres con mayor reactividad para los genes relacionados con angiogénesis se encontró una relación positiva para los cambios estructurales 
Tabla 1. Características de la población en estudio.

\begin{tabular}{|c|c|}
\hline Variable & $\mathbf{N}(\%)$ \\
\hline Edad (media, DE) & $52( \pm 10)$ \\
\hline $\begin{array}{l}\text { Edad por estratos } \\
<65 \text { años } \\
>65 \text { años }\end{array}$ & $\begin{array}{r}56(91.8) \\
5(8.2)\end{array}$ \\
\hline $\begin{array}{l}\text { Estado funcional (IK) } \\
<70 \\
>70 \\
\text { ND }\end{array}$ & $\begin{array}{l}10(16.4) \\
37(60.7) \\
14(23.0)\end{array}$ \\
\hline $\begin{array}{l}\text { Grado escolaridad } \\
\text { Primaria } \\
\text { Bachiller } \\
\text { Vocacional/técnico } \\
\text { Posgrado } \\
\text { Ninguno } \\
\text { ND }\end{array}$ & $\begin{array}{r}14(23.0) \\
9(14.8) \\
13(21.3) \\
1(1.6) \\
10(16.4) \\
14(23.0)\end{array}$ \\
\hline $\begin{array}{l}\text { Antecedente tabaquismo } \\
\text { No fumador } \\
\text { Fumador } \\
\text { ND }\end{array}$ & $\begin{array}{l}29(47.5) \\
12(19.7) \\
10(16.4)\end{array}$ \\
\hline Número de años de exposición al tabaco (media, DE) & $12( \pm 7)$ \\
\hline HIV (+) & 0 \\
\hline $\begin{array}{l}\text { Historia de lesión preneoplásica } \\
\mathrm{Si} \\
\text { No } \\
\mathrm{ND}\end{array}$ & $\begin{array}{l}13(21.3) \\
19(31.1) \\
29(47.5)\end{array}$ \\
\hline $\begin{array}{l}\text { Historia de infección por virus del papiloma humano (VPH) } \\
\mathrm{Si} \\
\text { No } \\
\text { ND }\end{array}$ & $\begin{array}{r}7(11.5) \\
26(42.5) \\
28(45.9)\end{array}$ \\
\hline $\begin{array}{l}\text { Histología } \\
\text { Escamoso } \\
\text { Adenocarcinoma } \\
\text { Adenoescamoso }\end{array}$ & $\begin{array}{r}58(95.1) \\
2(3.3) \\
1(1.6)\end{array}$ \\
\hline $\begin{array}{l}\text { Grado histológico } \\
\text { Gx } \\
\text { G1 } \\
\text { G2 } \\
\text { G3 }\end{array}$ & $\begin{array}{r}18(29.5) \\
10(16.4) \\
29(47.5) \\
4(6.6)\end{array}$ \\
\hline Tamaño tumoral (media, DE) & $6.4 \mathrm{~cm}( \pm 1.8)$ \\
\hline $\begin{array}{l}\text { Estado clínico (FIGO) } \\
\text { IIA } \\
\text { IIB } \\
\text { IIIA } \\
\text { IIIB } \\
\text { IVA } \\
\text { Desconocido }\end{array}$ & $\begin{array}{r}2(2.3) \\
29(47.5) \\
3(4.9) \\
23(37.7) \\
2(3.3) \\
2(3.3)\end{array}$ \\
\hline $\begin{array}{l}\text { Ganglios pélvicos positivos (biopsia escisional o BACAF) } \\
\mathrm{Si} \\
\text { No evaluados }\end{array}$ & $\begin{array}{r}5(8.2) \\
56(91.8)\end{array}$ \\
\hline $\begin{array}{l}\text { FIGO: Federation International Ginecology Oncology. } \\
\text { BACAF: biopsia por aspiración con aguja fina. }\end{array}$ & \\
\hline
\end{tabular}

valorados por la DMV ( $\mathrm{p}=0.027)$. La DMV no modificó la $\operatorname{SLP}(\mathrm{p}=0.60)$ ni la SG $(\mathrm{p}=0.66)$.

El $46 \%$ de las pacientes presentaron inmunorreactividad para EGFR sin que este hallazgo fuera modificado por el tamaño tumoral $(\mathrm{p}=0.49)$, el estado $(\mathrm{p}=0.40)$, y el grado histológico $(\mathrm{p}=0.12)$. El $57 \%$ de las pacientes con expresión positiva del EGFR tuvieron una alta reactividad para el VEGF
Tabla 2. Desenlaces principales después de la administración de la quimiorradiación.

\begin{tabular}{|lr|}
\hline Desenlaces & $\mathbf{N}(\%)$ \\
\hline Interrupciones no programadas en la teleterapia & \\
No & $33(54.1)$ \\
Si, por toxicidad & $13(21.3)$ \\
Si, por otras razones & $12(19.7)$ \\
ND & $3(4.9)$ \\
\hline Tratamiento completo con braquiterapia de alta tasa & \\
Si & $46(75.4)$ \\
No & $11(18.0)$ \\
ND & $4(6.6)$ \\
\hline Número de ciclos de carbo o cisplatino semanal & \\
1 & $2(3.3)$ \\
2 & $3(4.9)$ \\
3 & $7(11.5)$ \\
4 & $10(16.4)$ \\
5 & $16(26.2)$ \\
6 & $21(34.4)$ \\
ND & $2(3.3)$ \\
\hline Estado clínico postratamiento & \\
Ausencia de tumor & $28(45.9)$ \\
Tumor residual & $19(31.1)$ \\
Desconocido & $14(23.0)$ \\
\hline Estado tomográfico postratamiento & \\
Respuesta completa & $3(14.9)$ \\
Respuesta parcial & $29(47.5)$ \\
Enfermedad estable & $31(50.8)$ \\
Enfermedad en progresión & $23(37.7)$ \\
Desconocido & \\
\hline Progresión de la enfermedad & \\
Si & \\
No & \\
Desconocido & \\
\hline
\end{tabular}

Tabla 3. Expresión proteica en el tejido tumoral embebido en parafina y su relación con los principales desenlaces en estudio.

\begin{tabular}{|c|c|c|c|c|c|}
\hline Variable & $\begin{array}{c}\text { Resultado } \mathrm{N} \\
(\%)\end{array}$ & $\begin{array}{l}\text { SLP (meses, } \\
\text { IC95\%) }\end{array}$ & $\mathbf{P}$ & $\begin{array}{l}\text { SG (meses, } \\
\text { IC95\%) }\end{array}$ & $\mathbf{P}$ \\
\hline \multicolumn{6}{|l|}{ EGFR } \\
\hline Alterada & $28(45.9)$ & $3.0(1.7-5.3)$ & 0.69 & $20(12.4-28.2)$ & 0.030 \\
\hline Negativa & $26(42.6)$ & $5.2(0.3-11.7)$ & & $48.5(36.4-60.7)$ & \\
\hline ND & $7(11.5)$ & - & & & \\
\hline \multicolumn{6}{|l|}{ DMV } \\
\hline Normal & $21(34.4)$ & $2.7(1.8-3.5)$ & 0.60 & $25.6(0.8-58.3)$ & 0.66 \\
\hline Alterada & $31(50.8)$ & $6.7(4.2-8.9)$ & & $26.7(11.0-42.4)$ & \\
\hline ND & $9(14.8)$ & - & & - & \\
\hline \multicolumn{6}{|l|}{ VEGF } \\
\hline Baja & $24(39.3)$ & $3.0(0.7-5.3)$ & 0.65 & $58(44.5-71.5)$ & 0.026 \\
\hline Moderada & $10(16.4)$ & - & & - & \\
\hline Alta & $19(31.1)$ & $1.2(0.6-1.8)$ & & $18.7(15.1-22.4)$ & \\
\hline Ausente & $4(6.6)$ & $8.0(4.6-11.4)$ & & $26.6(9.0-44.2)$ & \\
\hline ND & $4(6.6)$ & - & & - & \\
\hline \multicolumn{6}{|l|}{ HIF } \\
\hline Alterada & $30(49.2)$ & $4.3(1.0-7.7)$ & 0.59 & $24.0(7.1-42.0)$ & 0.037 \\
\hline Negativa & $23(37.7)$ & 7.0 (4.3-9-7) & & $52.0(40.0-63.0)$ & \\
\hline ND & $8(13.1)$ & & & - & \\
\hline
\end{tabular}




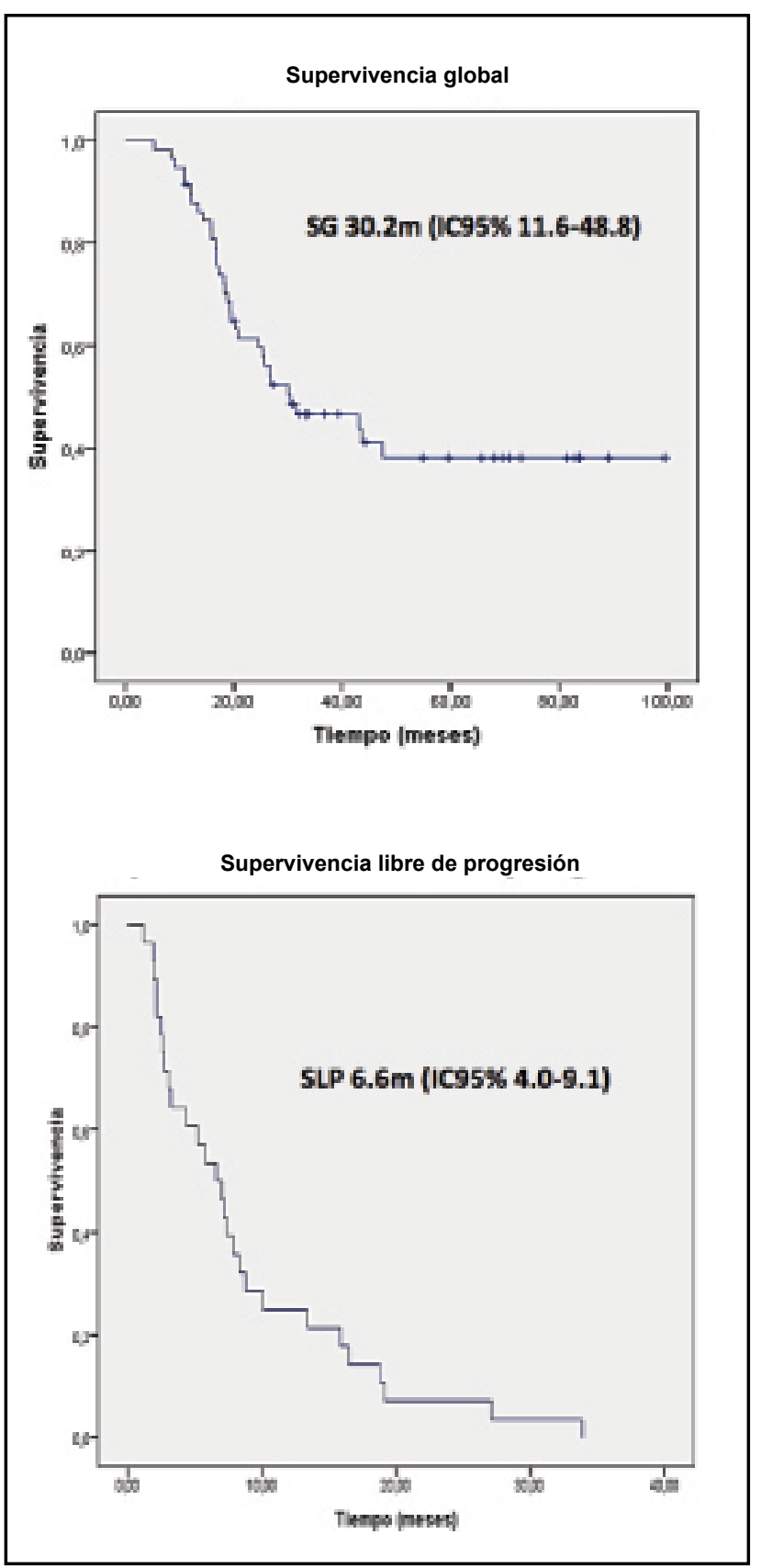

Figura 1. Supervivencia global y libre de progresión en la población general.

evento que se relacionó en esas 16 mujeres con un impacto negativo sobre la SG ( $\mathrm{p}=0.0001)$. El $50 \%$ de las pacientes tuvieron una expresión anormal del HIF siendo mayor entre quienes presentaban neoplasias moderadamente diferenciadas, tumores en estado IIIB, con elevación en el VEGF y la DMV; entre éstos hubo una correlación estadísticamente significativa para el ligando del VEGFR $(\mathrm{p}=0.04)$ y para la expresión del CD31 ( $\mathrm{p}=0.03)$.

El $31 \%$ de los sujetos en estudio no presentó ninguna de las cuatro alteraciones evaluadas, mientras $20,13,16$ y $18 \%$ tuvieron 1, 2, 3 y 4 anormalidades, respectivamente. En con-

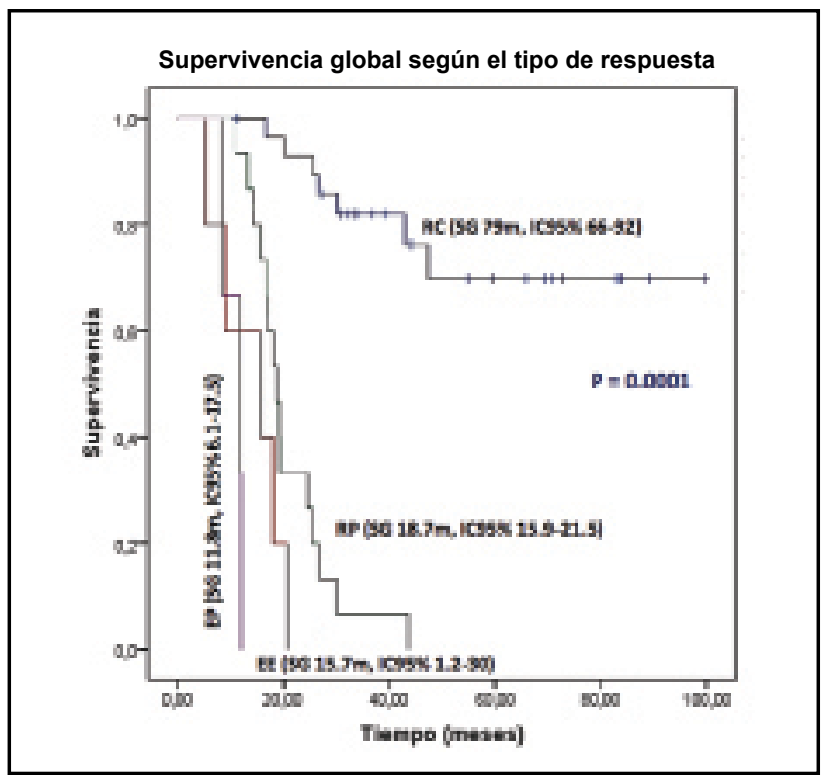

Figura 2. Supervivencia global según el tipo de respuesta a la quimiorradiación.

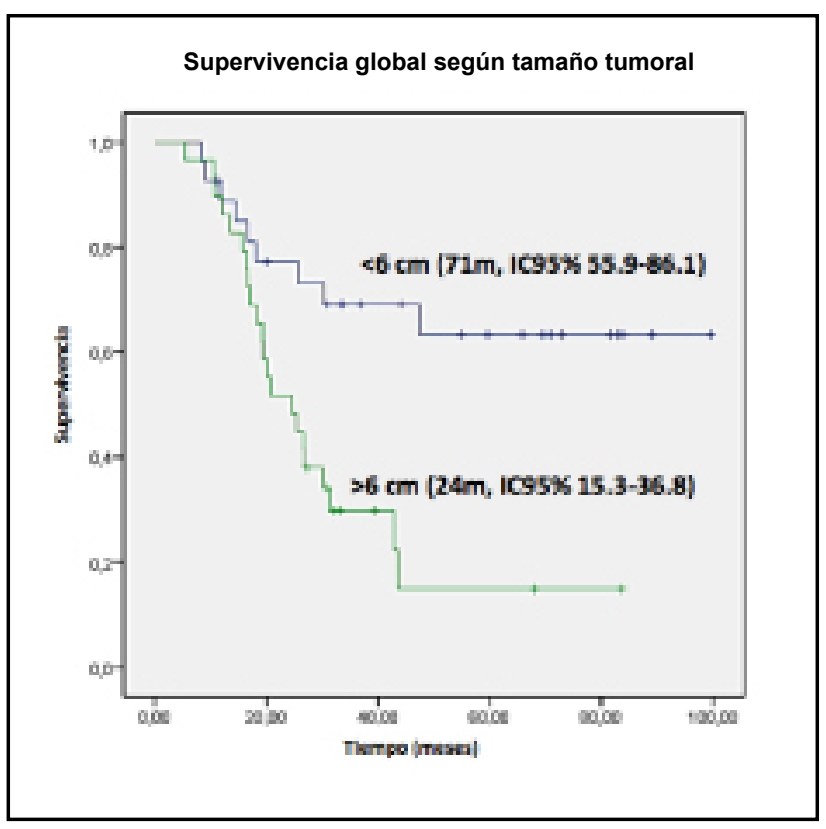

Figura 3. Supervivencia global según el tamaño tumoral (mayor y menor de $6 \mathrm{~cm}$ ).

junto la presencia de dos o más alteraciones no influyó sobre la SLP ( $\mathrm{p}=0.50)$, ni sobre la $\mathrm{SG}(\mathrm{p}=0.53)$.

La expresión anormal del EGFR, del VEGF y del HIF-1 $\alpha$, modificaron el curso de la SG sin afectar la SLP (Figuras 4-6). La Tabla 3 incluye los resultados para los desenlaces según la expresión proteica en el tejido tumoral embebido en parafina. Al término del seguimiento 57\% de las mujeres había muerto, evento influenciado en el análisis multivariado de riesgos proporcionales por la expresión del EGFR y del VEGF (Tabla 4). En 33 casos la causa de muerte estuvo relacionada con la progresión de la enfermedad especialmente a 
nivel locoregional, y en dos mujeres, fue imposible determinar el origen de este hecho.

\section{Discusión}

El cáncer de cérvix es considerado en la actualidad como un problema de salud pública global, con una elevada incidencia entre la población de mujeres de los países en vía de desarrollo, principalmente en los subgrupos de menor nivel socioeconómico y con pobre higiene personal. Entre los años 2002 y 2006 el INC (Instituto Nacional de Cancerología, Colombia) ubicó a las neoplasias del cérvix en el primer lugar de incidencia, lo que se traduce en cerca de 5600 casos/año o en 26 por 100000 mujeres durante el mismo periodo (38). Además, dicho tumor explica el $12 \%$
Tabla 4. Análisis multivariado para la supervivencia global (Modelo de Cox).

\begin{tabular}{|l|c|}
\hline Variable & P(IC95\%) \\
\hline Expresión EGFR & $0.049(1.47-3.99)$ \\
Densidad microvascular & $0.75(0.30-2.35)$ \\
Expresión VGEF & $0.038(1.03-2.89)$ \\
Grado histológico & $0.15(0.52-54.50)$ \\
Respuesta imaginológica al término del tratamiento & $0.11(0.88-3.06)$ \\
\end{tabular}

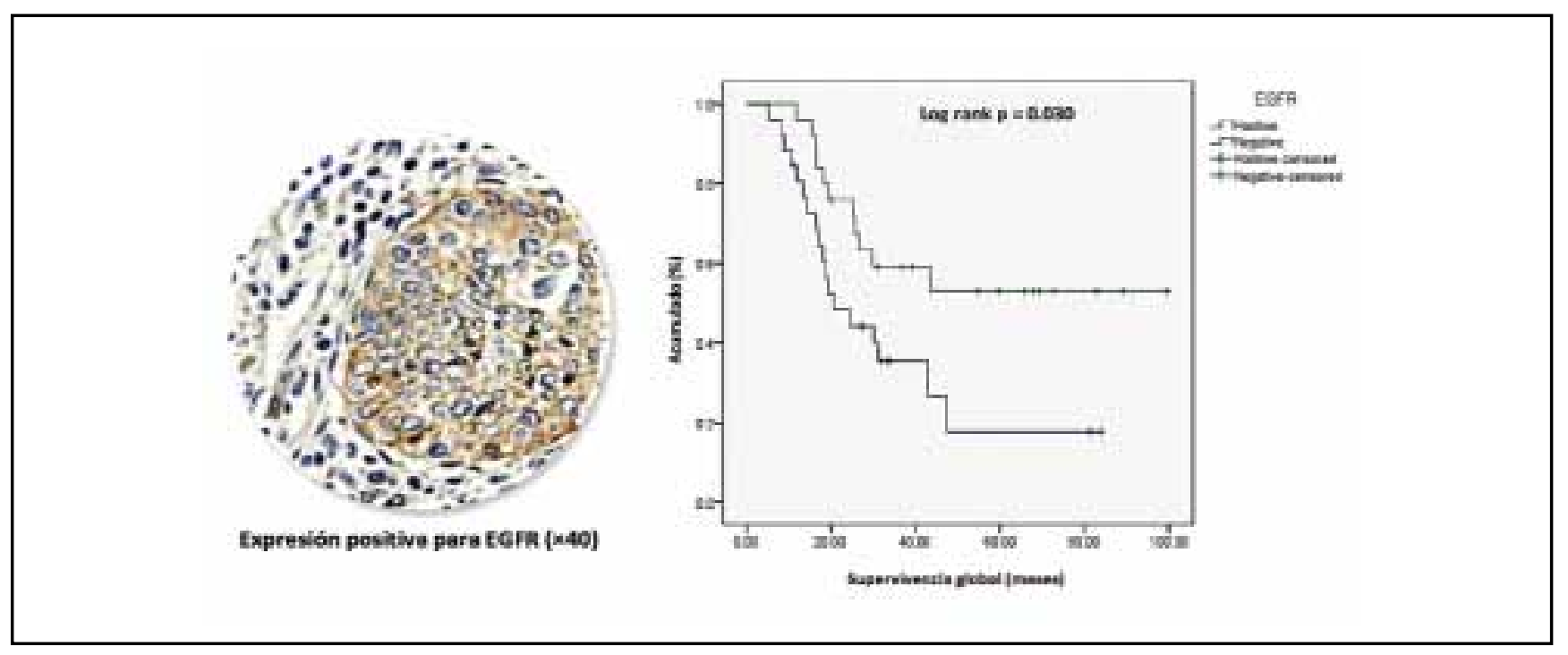

Figura 4. Supervivencia global según la expresión de EGFR.
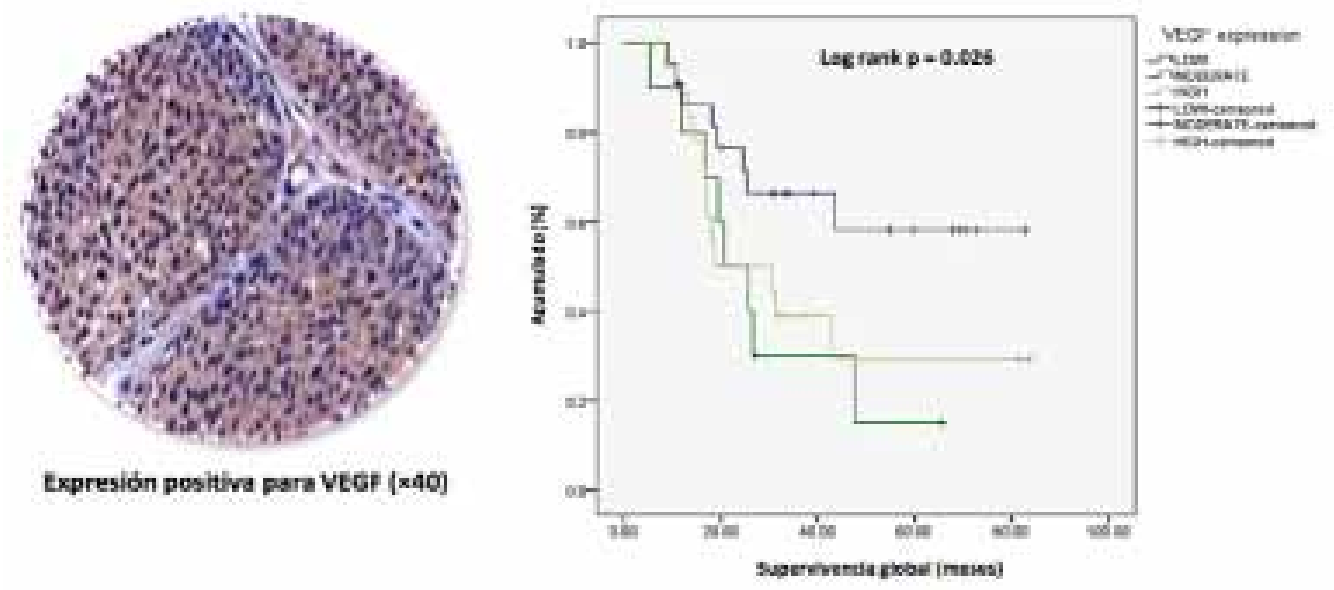

Figura 5. Supervivencia global según la expresión de VEGF. 

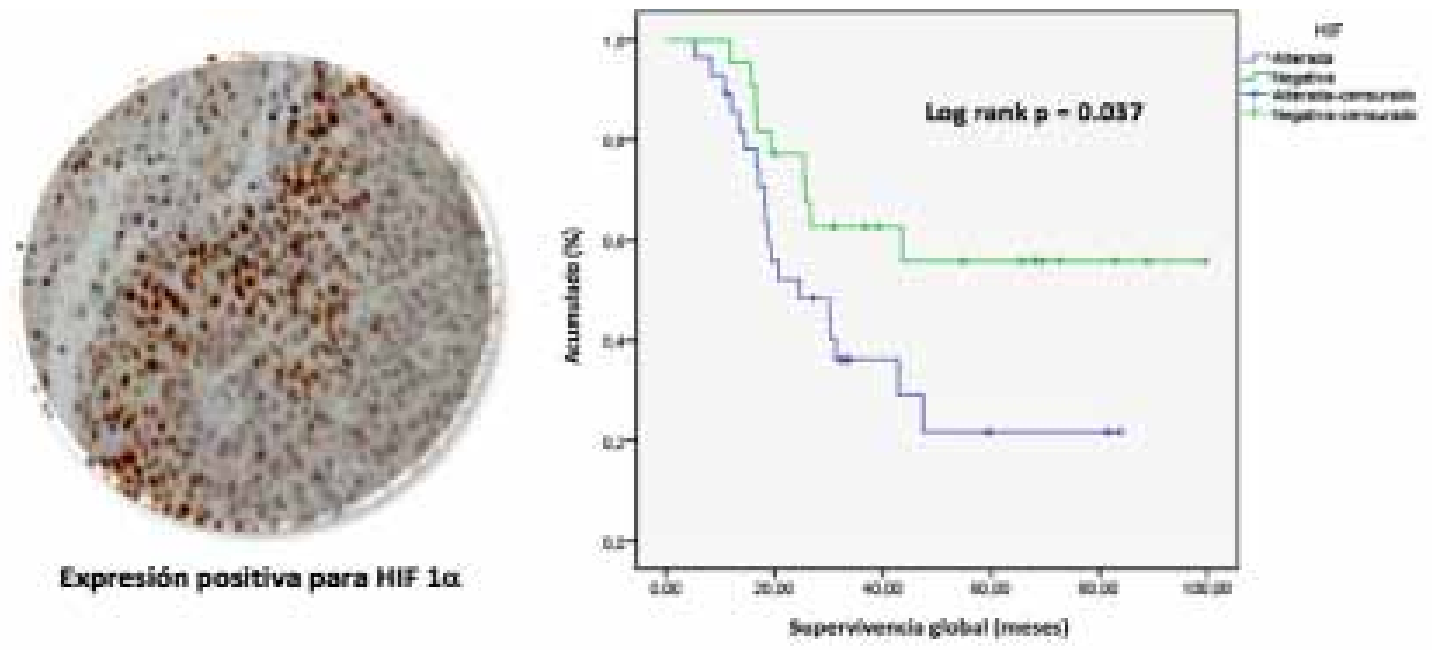

Figura 6. Supervivencia global según la expresión de HIF-l $\alpha$.
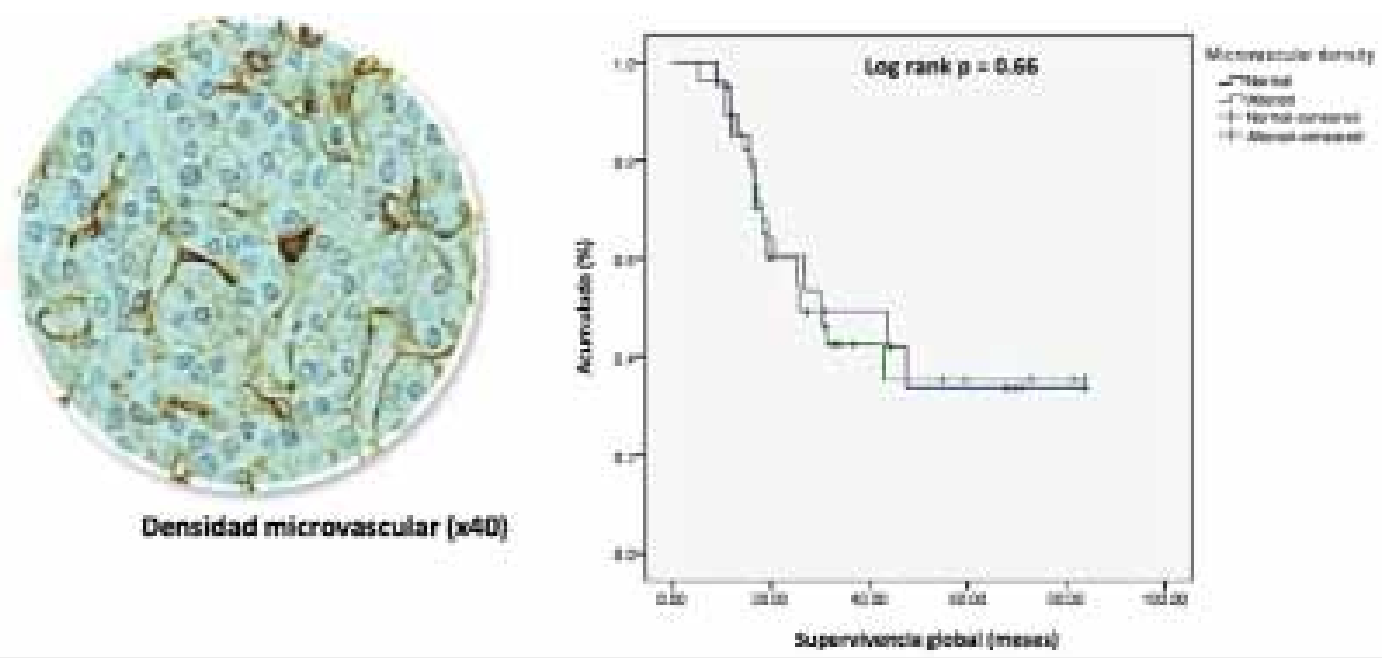

Figura 7. Supervivencia global según la densidad microvascular (DMV).

de las muertes por patologías crónicas entre la población de mujeres menores de 45 años (7). La gran mayoría (aproximadamente $60 \%$ ) de los casos hallados en nuestro entorno se encuentran agrupados entre las lesiones localmente avanzadas que requieren tratamiento con quimiorradiación usando cisplatino como coadyuvante. Múltiples estudios han intentado mejorar las tasas de respuesta global y la SLP y SG en esta población utilizando medicamentos que permitan bloquear nuevos blancos moleculares alterados por amplificación, sobreexpresión o mutaciones que favorecen la supervivencia y proliferación celular (39).

Una revisión sistemática que agrupó 25 experimentos clínicos $(n=3452)$ demostró que la administración de quimiorradiación versus radioterapia sola reduce el riesgo de muerte en $19 \%$, lo cual se traduce en un beneficio sobre la SG a cinco años que oscila alrededor de 10-12\% (40). El presente estudio encontró una tasa de respuesta imaginológica similar a la descrita previamente en la literatura, al igual que una SG a tres años de $66 \%$, cifra equivalente a la hallada en los estudios que sirvieron para estandarizar el tratamiento concomitante en la población de mujeres con neoplasias localmente avanzadas (41).

Los tumores de cérvix son el resultado de la expresión alterada de múltiples genes modificados por las oncoproteinas E6 y E7 del VPH. Achary y colaboradores, determinaron que las diferencias en la expresión génica de las células tumorales en el cérvix predicen la radio y quimiosensibilidad; los cambios en 52 genes conductores determinaron el comportamiento biológico de los tumores escamosos, siendo dominantes algunos como el EGFR, el VEGF, el HIF-1 $\alpha$ y $2 \alpha$, el HYAL2 (hialuronoglucosaminidasa 2), el SV2A (synaptic vesicle glycoprotein $2 A$ ) y las caspasa $10(42,43)$. 
El EGFR se encuentra alterado en tres cuartas partes de las pacientes con cáncer de cérvix, hallazgo que ha estimulado la evaluación de terapias dirigidas contra el dominio externo del receptor (cetuximab, matuzumab y panitumumab); de igual forma, se han valorado diversos inhibidores tirosinquinasa con resultados divergentes (erlotinib, gefitinib, lapatinib). Las alteraciones en este receptor se han asociado a pobre pronóstico debido a la capacidad para modular la respuesta del cáncer a la quimio y radioterapia. Liang y colaboradores determinaron que la teleterapia aumenta la biodisponibilidad y externalización del receptor, por lo que su bloqueo podría explicar el aumento en la respuesta de las mujeres con cáncer de cérvix expuestas a medicamentos dirigidos contra este blanco (44). La evaluación de mujeres con cáncer de cérvix en Colombia encontró una expresión elevada del EGFR en $46 \%$ de la población, hallazgo que no fue determinante sobre la SLP, pero que modificó positivamente la $\mathrm{SG}$ en el análisis uni y multivariado. En concordancia, la elevación en la expresión del EGFR se asoció con una mayor DMV ( $\mathrm{p}=0.016)$, con un aumento significativo en el VEGF ( $\mathrm{p}=0.0001)$ y con la elevación en el HIF-1 $\alpha$ ( $\mathrm{p}=0.0001)$. Por el contrario, no hubo asociación entre el tamaño tumoral y la calificación del EGFR por inmunohistoquímica.

Varios estudios clínicos han demostrado la utilidad creciente de diversos compuestos dirigidos contra el EGFR en pacientes con carcinoma escamoso y adenoescamoso de cérvix $(45,46)$. Los más promisorios y avanzados se han publicado con erlotinib (47-49), sin embargo también se han evaluado el cetuximab como monoterapia (GOG-0227E), en conjunto con radioterapia pélvica (GOG-9918) y en asociación con cisplatino en tumores recurrentes (GOG0076DD). Sólo un estudio valoró la utilidad del gefitinib como segunda o tercera línea en pacientes con enfermedad avanzada (50-52).

Recientemente, un estudio fase I demostró la dosis máxima tolerada (MTD) y la seguridad del erlotinib combinado con cisplatino y radioterapia pélvica para el manejo del carcinoma de cérvix localmente avanzado (48). El tratamiento con el inhibidor no generó radiodermitis o diarrea limitante y la gran mayoría de los pacientes presentaron toxicidad menor (33-66\% presentaron radiodermitis y diarrea grado 1-2, respectivamente), motivo por el cual se seleccionó la dosis de $150 \mathrm{mg}$ /día que se administró durante la teleterapia y la braquiterapia endocavitaria. Posteriormente, se presentaron los resultados de la fase II del mismo trabajo que incluyó 34 pacientes entre los que se encontró toxicidad menor, una tasa de respuesta completa de 91,3\% (IC95\% 70,5 a 98,5) y parcial de $8,7 \%$ (49). Después de una mediana de seguimiento de nueve meses (rango 3-25), ninguno de los 23 pacientes evaluables había progresado, datos que indicaron que la combinación de la quimiorradiación más el erlotinib mejora de forma significativa los resultados obtenidos con el tratamiento histórico estándar. Estos hallazgos, y la repercusión de la expresión del EGFR en nuestra población estimulan el control de esta vía como intervención complementaria en mujeres con lesiones derivadas del cuello uterino.

El análisis de la expresión de múltiples genes relacionados con la angiogénesis, vasculogénesis y linfangiogénesis ha permitido entender la biología y el control celular en distintas neoplasias incluyendo el cáncer de cérvix. Múltiples investigadores reportaron que el estado del VEGFR incide sobre la respuesta y progresión en pacientes con enfermedad localmente avanzada $(53,54)$; del mismo modo el GOG observó que un aumento en la expresión del VEGF (mayor o igual a 200) se encuentra en $66 \%$ de las pacientes con cáncer de cérvix, hallazgo que se relacionó con la positividad del CD31 (encontrado en 34\% de las pacientes) y con la elevación de la TSP1 (65\% de los casos) (55). A diferencia de estos resultados nuestro estudio demostró una reducción en la SG para la población que presentaba una expresión alterada del VEGF. Estos resultados se confirmaron al demostrar una relación directa y proporcional entre el mayor compromiso vascular medido por la expresión tisular del VEGF, y por la DMV cuantificada según la inmunorreacción del CD31 $(\mathrm{p}=0.027)$. La elevación del VEGF también se correlacionó en un aumento en el HIF- $1 \alpha(\mathrm{p}=0.07)$.

El aumento en la DMV se asocia con la alteración de otros marcadores derivados del endotelio vascular como el factor VIII, el CD34, la interleuquina 8 (IL8), el factor de necrosis tumoral $\alpha$ (TNF $\alpha)$ y el VEGF. Un estudio que valoró 117 mujeres con carcinoma de cérvix estado IB2 encontró una relación directa y proporcional entre la expresión de VEGF, la invasividad tumoral, el compromiso ganglionar y el volumen de la neoplasia (21). Hockel y colaboradores determinaron que el crecimiento de los carcinomas escamosos del cérvix se acompaña de una hipervascularización en la periferia del estroma y de una hipovascularidad en el núcleo tumoral, punto donde la DMV es inferior a 40 vasos $/ \mathrm{mm}^{2}$; este hecho se asoció con la agresividad local de la neoplasia e influenció la SLP y SG en 52 pacientes (56). Estos datos fueron concordantes con los encontrados en el Instituto Nacional de Cancerología de México (INCAN), donde se estudiaron 118 pacientes que tuvieron un peor pronóstico al aumentar la DMV sobre un límite de 20 (57). Por el contrario, nuestro estudio no encontró ninguna relación entre los desenlaces primarios y la alteración de la DMV utilizando un patrón de medición previamente descrito en la literatura.

La tensión de oxígeno tiene un papel crítico en la regulación de la expresión génica del VEGF. El HIF-1 es el regulador principal de la respuesta transcripcional secundaria a la hipoxia, aunque otros factores de transcripción, como AP-1, SP-1 y NFkB, tienen sitios de unión en la región del promotor de VEGF. Varios estudios han relacionado la sobreexpresión del VEGF con el potencial de metástasis y con la posibilidad de respuesta a la quimiorradiación en diversas neoplasias ginecológicas. Bachtiary informó una mayor probabilidad de falla local y a distancia en mujeres con cáncer de cérvix que tuvieron niveles elevados de VEGF en plasma (mayores de $244 \mathrm{pg} / \mathrm{ml}$ ), evento que se relacionó 
con un aumento en la expresión proteica cuantificada antes de la administración de la radioterapia (53). De igual forma, Zusterzeel concluyó que la elevación en los niveles circulantes de VEGF se asoció con un mayor estado tumoral, con la posibilidad de documentar un tumor mayor de $2 \mathrm{~cm}$ y con una probabilidad superior de evidenciar la presencia de los subtipos más agresivos del VPH (58).

Dado que la angiogénesis se encuentra claramente relacionada con el desarrollo y la progresión del cáncer de cérvix, varios estudios han evaluado la eficacia y seguridad de agentes como el bevacizumab en mujeres con enfermedad recurrente o metastásica. Este agente demostró una tasa de respuesta de $11 \%$ y una proporción baja de pacientes sin progresión de la enfermedad después de seis meses de iniciada la intervención (59). Algunos reportes adicionales soportan el uso de este y otros antiangiogénicos en combinación con carboplatino y paclitaxel como parte del tratamiento sistémico del carcinoma de cérvix avanzado (59-62).

De acuerdo con el registro institucional de cáncer del INC, en el año 2000 se atendieron 651 pacientes con cáncer de cérvix en esa institución; la mayoría tenía neoplasias del tipo escamocelular, un poco más de la mitad presentaba tumores mayores de $5 \mathrm{~cm}$ y estados clínicos IIIB o superiores, motivo por el cual $53.3 \%$ fue tratado con radioterapia asociada o no a quimioterapia con base en platino; de estas, sólo $13 \%$ recibió la quimioterapia de forma regular, a diferencia de los casos incluidos en nuestra serie donde superó $50 \%$. Al término del seguimiento, $66 \%$ de las mujeres estaban vivas y $31.6 \%$ había muerto a causa de la enfermedad; la mediana de SG fue de 54.3 meses, superior a la encontrada en nuestro estudio. No obstante, la tercera parte de los casos evaluados por Pardo y colaboradores correspondían a tumores in situ y estados tempranos $(n=157)$. Al igual que nosotros, la $S G$ de las mujeres tratadas en el INC se vio afectada por el tamaño tumoral; sin embargo, en dicha cohorte también influyó el nivel educativo máximo alcanzado, el régimen de afiliación al sistema general de seguridad social y el estado tumoral, siendo este último el factor de mayor valor dado que la supervivencia a cinco años en los estados III y IV fue de $37-0 \%$, respectivamente (63).

Los resultados del tratamiento del carcinoma de cérvix localmente avanzado distan de ser óptimos; sin embargo, el desarrollo de la biología molecular tumoral permitirá determinar la presencia de subgrupos que se benefician de intervenciones puntuales. Este estudio permite confirmar el valor pronóstico de varios genes relacionados con la supervivencia y proliferación de los tumores escamosos de origen ginecológico, favoreciendo la introducción de nuevas hipótesis acerca de la utilidad potencial de moléculas dirigidas contra las vías de señalización dependientes del EGFR y de algunos elementos claves en la angiogénesis.

\section{Conclusiones}

Los desenlaces encontrados en la serie son equivalentes a los de otros estudios reportados previamente.
Tres condiciones influyeron positivamente sobre la supervivencia sin modificar el curso de la supervivencia libre de progresión, los niveles de expresión del EGFR, VEGF y el volumen tumoral inicial.

Estos resultados tienen relación con el pronóstico del cáncer de cérvix localmente avanzado; dos de los genes comprometidos pueden ser controlados con la administración de terapias dirigidas contra la angiogénesis y la proliferación tumoral a través de la vía dependiente del receptor para el factor de crecimiento epidérmico.

\section{Conflictos de interés}

Andrés Felipe Cardona, Hernán Carranza, Jorge Miguel Otero, Carlos Vargas y Carlos Castro son miembros de la Fundación para la Investigación Clínica y Molecular Aplicada del Cáncer - FICMAC (Bogotá, D.C., Colombia).

\section{Agradecimientos}

Los autores agradecen la colaboración de Teresa Castro en el proceso de identificación y recolección de la información de los casos incluidos en el estudio. De igual forma, la generosa contribución de la familia Silberman, quienes han promovido con altruismo el desarrollo de la investigación en cáncer en Colombia.

\section{Referencias}

1. Pisani P, Parkin DM, Bray F. Estimates of the worldwide mortality from 25 cancers in 1990. Int J Cancer 1999; 83: 18-29.

2. Frazer IH, Lowy DR, Schiller JT. Prevention of cancer through immunization: Prospects and challenges for the 21st century. Eur J Immunol 2007; 37 Suppl 1: S148-55.

3. Agosti JM, Goldie SJ. Introducing HPV vaccine in developing countries-key challenges and issues. N Engl J Med 2007; 356(19): 1908-10.

4. Monk BJ, Tewari KS. Invasive cervical cancer, in DiSaia PJ, Creasman WT (eds): Clinical Gynecologic Oncology (ed 7). Philadelphia, PA, Mosby Publishers, 2007.

5. Robles SC, White F, Peruga A. Trends in cervical cancer mortality in the Americas. Bull Pan Am Health Org 1996; 30: 290-301.

6. Pabón A. La mortalidad en Colombia 1953-1991. [Mortality in Columbia $1953-$ 1991]. Santafé de Bogotá: Instituto Nacional de Salud; 1993.

7. Ministerio de Salud (República de Colombia). Mortalidad y años de vida ajustados por discapacidad como medidas de la carga de enfermedad Colombia 1985-1995 [Mortality and DALY's as a measure of burden of disease, Colombia 1985-1995]. Santafé de Bogotá: Imprenta Nacional, 1999.

8. Keys H, Gibbons SK. Optimal management of locally advanced cervical carcinoma. J Natl Cancer Inst Monogr 1996; 21: 89-92.

9. Morris M, Eifel PJ, Lu J, et al. Pelvic radiation with concurrent chemotherapy compared with pelvic and para-aortic radiation for high-risk cervical cancer. $N$ Engl J Med 1999; 340: 1137-1143.

10. Peters WA III, Liu PY, Barrett II RJ, et al. Concurrent chemotherapy and pelvic radiation therapy compared with radiotherapy alone as adjuvant therapy after radical surgery in high-risk early stage-cancer of the cervix. J Clin Oncol 2000; 18: 1606-1613.

11. Cancer trials. NCI issues clinical announcement on cervical cancer chemotherapy plus radiation improves survival, http://www.cancer.gov.newscenter/ cervicalcancer.html

12. Datta NR, Agrawal S. Does the evidence support the use of concurrent chemoradiotherapy as a standard in the management of locally advanced cancer of the cervix, especially in developing countries? Clin Oncol 2006; 18(4): 306-12.

13. Muñoz N, Bosch FX, de Sanjosé S, Herrero R, Castellsagué X, Shah KV, et al. Epidemiologic classification of human papillomavirus types associated with cervical cancer. N Eng J Med 2003; 348: 518-527.

14. Münger K, Howley PM. Human papillomavirus immortalization and transformation functions. Virus Res 2002; 89: 213-228.

15. Mork J, Lie AK, Glattre E, Hallmans G, Jellum E, Koskela P, et al. Human papillomavirus infection as a risk factor for squamous-cell carcinoma of the head and neck. N Engl J Med 2001; 344(15): 1125-31.

16. Veikkola T, Karkkainen M, Claesson-Welsh L, Alitalo K. Regulation of angiogenesis via vascular endothelial growth factor receptors. Cancer Res 2000 ; 60: $203-212$. 
17. Randall LM, Monk BJ, Darcy KM, Tian C, Burger RA, Liao SY. Markers of angiogenesis in high-risk, early-stage cervical cancer: A Gynecologic Oncology Group study. Gynecol Oncol 2009; 112(3): 583-9.

18. Obermair A, Wanner C, Bilgi S, Speiser P, Kaider A, Reinthaller A, et al. Tumor angiogenesis in stage IB cervical cancer: correlation of microvessel density with survival. Am J Obstet Gynecol 1998; 178(2): 314-9.

19. Rutgers JL, Mattox TF, Vargas MP. Angiogenesis in uterine cervical squamous cell carcinoma. Int J Gynecol Pathol 1995; 14(2): 114-8.

20. Kainz C, Speiser P, Wanner C, Obermair A, Tempfer C, Sliutz G, et al. Prognostic value of tumour microvessel density in cancer of the uterine cervix stage IB to IIB. Anticancer Res 1995; 15: 1549-1551.

21. Lee IJ, Park KR, Lee KK, Song JS, Lee KG, Lee JY, et al. Prognostic value of vascular endothelial growth factor in Stage IB carcinoma of the uterine cervix. Int J Radiat Oncol Biol Phys 2002; 54: 768-79.

22. Lu ZH, Wright JD, Belt B, Cardiff RD, Arbeit JM. Hypoxia-inducible factor-1 facilitates cervical cancer progression in human papillomavirus type 16 transgenic mice. Am J Patol 2007; 171(2): 667-681.

23. Moeller BJ, Dreher MR, Rabbani ZN, Schroeder T, Cao Y, Li CY. Pleiotropic effects of HIF-1 blockade on tumor radiosensitivity. Cancer Cell 2005; 8: $99-110$.

24. Liu J, Zhang J, Wang X, Li Y, Chen Y, Li K, Zhang J, Yao L, Guo G. HIF-1 and NDRG2 contribute to hypoxia-induced radioresistance of cervical cancer Hela cells. Exp Cell Res 2010; 316(12): 1985-93.

25. Nakamura M, Bodily JM, Beglin M, Kyo S, Inoue M, Laimins LA. Hypoxiaspecific stabilization of HIF-1alpha by human papillomaviruses. Virology 2009; 387(2): 442-8.

26. Dellas K, Bache M, Pigorsch SU, Taubert H, Kappler M, Holzapfel D, et al. Prognostic impact of HIF-1alpha expression in patients with definitive radiotherapy for cervical cancer. Strahlenther Onkol 2008; 184(3): 169-74.

27. Burri P, Djonov V, Aebersold DM, Lindel K, Studer U, Altermatt HJ, et al. Significant correlation of hypoxia-inducible factor-1alpha with treatment outcome in cervical cancer treated with radical radiotherapy. Int J Radiat Oncol Biol Phys 2003; 56(2): 494-501.

28. Ishikawa H, Sakurai H, Hasegawa M, Mitsuhashi N, Takahashi M, Masuda $\mathbf{N}$, et al. Expression of hypoxic-inducible factor 1alpha predicts metastasisfree survival after radiation therapy alone in stage IIIB cervical squamous cell carcinoma. Int J Radiat Oncol Biol Phys 2004; 60(2): 513-21.

29. Hutchison GJ, Valentine HR, Loncaster JA, Davidson SE, Hunter RD, Roberts SA, et al. Hypoxia-inducible factor 1-alpha expression as an intrinsic marker of hypoxia: correlation with tumor oxygen, pimonidazole measurements, and outcome in locally advanced carcinoma of the cervix. Clin Cancer Res 2004; 10(24): 8405-12.

30. Speake G, Holloway B, Costello G. Recent developments related to the EGFR as a target for cancer chemotherapy. Curr Opin Pharmacol 2005; 5(4): 343-9.

31. Ghosh S, Liu XP, Zheng Y, Uckun FM. Rational design of potent and selective EGFR tyrosine kinase inhibitors as anticancer agents. Curr Cancer Drug Targets. 2001; 1(2): 129-40.

32. Noordhuis MG, Eijsink JJ, Ten Hoor KA, Roossink F, Hollema H, Arts HJ, et al. Expression of epidermal growth factor receptor (EGFR) and activated EGFR predict poor response to (chemo)radiation and survival in cervical cancer. Clin Cancer Res 2009; 15(23): 7389-97.

33. National Cancer Institute. Institute Common Terminology Criteria for Adverse Events (CTCAE) version 3.0. URL available from http://www.fda.gov/cder/ cancer/ toxicityframe.htm; Accessed in November 2008.

34. Eisenhauer EA, Therasse P, Bogaerts J, Schwartz LH, Sargent D, Ford R, et al. New response evaluation criteria in solid tumours: revised RECIST guideline (version 1.1). Eur J Cancer 2009; 45(2): 228-47.

35. Kimura S, Kitadai Y, Tanaka S, Kuwai T, Hihara J, Yoshida K, Toge T, Chayama K. Expression of hypoxia-inducible factor (HIF)-1alpha is associated with vascular endothelial growth factor expression and tumour angiogenesis in human oesophageal squamous cell carcinoma. Eur J Cancer 2004; 40(12): 1904-1912.

36. Tjalma W, Van Marck E, Weyler J, Dirix L, Van Daele A, Goovaerts G, et al. Quantification and prognostic relevance of angiogenic parameters in invasive cervical cancer. Br J Cancer 1998; 78: 170-4.

37. Weidner N, Semple JP, Welch WR, Folkman J. Tumour angiogenesis and metastasis-Correlation in invasive breast carcinoma. N Engl J Med 1991; 324: $1-8$.

38. http://www.cancer.gov.co/documentos/Incidencia/Tabla\%2084.pdf

39. Vrdoljak E, Hamm W. Multimodality therapy for locally advanced cervical carcinoma: state of the art and future directions. J Clin Oncol 2007; 25(20): 2952-65.

40. Chemoradiotherapy for Cervical Cancer Meta-Analysis Collaboration. Reduc- ing uncertainties about the effects of chemoradiotherapy for cervical cancer: a systematic review and meta-analysis of individual patient data from 18 randomized trials. J Clin Oncol 2008; 26(35): 5802-12.

41. Rose PG, Bundy BN. Chemoradiation for locally advanced cervical cancer: does it help?. J Clin Oncol 2002; 20: 891-893.

42. Achary MP, Jaggernauth W, Gross E, Alfieri A, Klinger HP, Vikram B. Cell lines from the same cervical carcinoma but with different radiosensitivities exhibit different cDNA microarray patterns of gene expression. Cytogenet Cell Genet 2000; 91: 39-43.

43. Grigsby PW, Watson M, Powell MA, Zhang Z, Rader JS. Gene expression patterns in advanced human cervical cancer. Int J Gynecol Cancer 2006; 16: 562-567.

44. Liang K, Ang KK, Milas L, Hunter N, Fan Z. The epidermal growth factor receptor mediates radioresistance. Int J Radiat Oncol Biol Phys 2003; 57(1): 246-54.

45. Baselga J, Norton L, Masui H, Pandiella A, Coplan K, Miller WH Jr, et al Antitumor effects of doxorubicin in combination with anti-epidermal growth factor receptor monoclonal antibodies. J Natl Cancer Inst 1993; 85(16): 1327-33.

46. Fan Z, Baselga J, Masui H, Mendelsohn J. Antitumor effect of anti-epiderma growth factor receptor monoclonal antibodies plus cis-diamminedichloroplatinum on well established A431 cell xenografts. Cancer Res 1993; 53(19): 4637-42.

47. Milano G, Magne N. Anti-EGFR and radiotherapy. Cancer Radiother 2004 8: $380-2$.

48. Nogueira-Rodrigues A, do Carmo CC, Viegas C, Erlich F, Camisão C Fontão K, et al. Phase I trial of erlotinib combined with cisplatin and radiotherapy for patients with locally advanced cervical squamous cell cancer. Clin Cancer Res 2008; 14(19): 6324-9.

49. Ferreira CG, Erlich F, Carmo CC, Viegas C, Cidade IJ, Camisao CC, et al. Erlotinib combined with cisplatin and radiotherapy for patients with locally advanced squamous cell cervical cancer: A phase II trial. J Clin Oncol 2008; 26: 5511.

50. Goncalves A, Fabbro M, Lhommé C, Gladieff L, Extra JM, Floquet A, et al. A phase II trial to evaluate gefitinib as second- or third-line treatment in patients with recurring locoregionally advanced or metastatic cervical cancer. Gynecol Oncol 2008; 108(1): 42-6.

51. Herrera FG, Vidal L, Oza A, Milosevic M, Fyles A. Molecular targeted agents combined with chemo-radiation in the treatment of locally advanced cervix cancer. Rev Recent Clin Trials 2008; 3(2): 111-20.

52. Tewari KS, Monk BJ. Recent achievements and future developments in advanced and recurrent cervical cancer: trials of the Gynecologic Oncology Group. Semin Oncol 2009; 36(2): 170-80.

53. Bachtiary B, Selzer E, Knocke TH, Pötter R, Obermair A. Serum VEGF levels in patients undergoing primary radiotherapy for cervical cancer: impact on progression-free survival. Cancer Lett 2002; 179: 197-203.

54. Ueda M, Terai Y, Yamashita Y, Kumagai K, Ueki K, Yamaguchi H, et al Correlation between vascular endothelial growth factor-C expression and invasion phenotype in cervical carcinomas. Int J Cancer 2002; 98: 335-343.

55. Randall LM, Monk BJ, Darcy KM, Tian C, Burger RA, Liao SY, et al Markers of angiogenesis in high-risk, early-stage cervical cancer: A Gynecologic Oncology Group study. Gynecol Oncol 2009; 112(3): 583-9.

56. Höckel S, Schlenger K, Vaupel P, Höckel M. Association between host tissue vascularity and the prognostically relevant tumor vascularity in human cervical cancer. Int J Oncol 2001; 19(4): 827-32.

57. Cantu De León D, López-Graniel C, Frias Mendivil M, Chanona Vilchis G, Gómez C, De La Garza Salazar J. Significance of microvascular density (MVD) in cervical cancer recurrence. Int J Gynecol Cancer 2003; 13(6): 856-62.

58. Zusterzeel PL, Span PN, Dijksterhuis MG, Thomas CM, Sweep FC, Massuger LF. Serum vascular endothelial growth factor: a prognostic factor in cervical cancer. J Cancer Res Clin Oncol 2009; 135: 283-290.

59. Monk BJ, Sill MW, Burger RA, Gray HJ, Buekers TE, Roman LD. Phase II trial of bevacizumab in the treatment of persistent or recurrent squamous cell carcinoma of the cervix: a gynecologic oncology group study. J Clin Oncol 2009; 27(7): 1069-74

60. Monk BJ, Willmott LJ, Sumner DA. Anti-angiogenesis agents in metastatic or recurrent cervical cancer. Gynecol Oncol 2010; 116(2): 181-6.

61. Tan SJ, Juan YH, Fu PT, Yu MH, Lai HC. Chemotherapy with low-dose bevacizumab and carboplatin in the treatment of a patient with recurrent cervical cancer. Eur J Gynaecol Oncol 2010; 31(3): 350-3.

62. Takano M, Kikuchi Y, Kita T, Goto T, Yoshikawa T, Kato M, et al. Complete remission of metastatic and relapsed uterine cervical cancers using weekly administration of bevacizumab and paclitaxel/carboplatin. Onkologie 2009; 32(10): 595-7.

63. Pardo C, Cendales R. Survival analysis of cervical cancer patients. Biomédica 2009; 29: 437-47. 